\title{
In Situ Hydroxyapatite Synthesis: Influence of Collagen on Its Structural and Morphological Characteristic
}

\author{
Luis C. Mendes, Geysy L. Ribeiro ${ }^{*}$, Raphaella C. Marques
}

Instituto de Macromoléculas Professora Eloísa Mano (IMA), Universidade Federal do Rio de Janeiro (UFRJ), Rio de Janeiro, Brasil. Email:" geysylopes@ima.ufrj.br

Received May $17^{\text {th }}, 2012$; revised June $15^{\text {th }}, 2012$; accepted July $11^{\text {th }}, 2012$

\begin{abstract}
Hydroxyapatite (HA) was synthesized in situ by the precipitation method, with and without the presence of collagen (COLL), to study its influence on HA's structural and morphological characteristics. The material was characterized by energy dispersive X-ray spectroscopy (EDX), Fourier transform infrared spectroscopy (FT-IR), wide-angle X-ray diffraction (WAXD), thermogravimetric analysis (TG) and scanning electron microscopy (SEM). The Ca/P molar ratio was influenced by collagen addition- 1.89 and 2.38 for samples without and with collagen, respectively. The WAXD pattern revealed better resolution and intensity besides higher crystallinity degree of the HA in the presence of collagen. The photomicrographs showed a strong influence of collagen on the HA morphology.
\end{abstract}

Keywords: Hydroxyapatite; Collagen; In Situ; Precipitation Method; Morphology

\section{Introduction}

Calcium phosphate apatites make up an important class of biomaterial, with hydroxyapatite (HA), $\mathrm{Ca}_{10}\left(\mathrm{PO}_{4}\right)_{6}(\mathrm{OH})_{2}$, being the most important due to its similarities with the mineral constituents of bone tissue and tooth enamel and dentin [1-3]. HA has excellent biocompatibility, displaying properties of osteoinduction, osteoconduction and osteointegration without cellular toxicity $[4,5]$. Therefore, $\mathrm{HA}$ is one of the most biocompatible materials known. As such, it has been studied for potential applications in areas such as tissue engineering, orthopedics and dentistry [6].

Collagen (COLL) is a natural and fibrous polymer constituting about $30 \%$ of all vertebrates' body proteins. There are more than 26 genetically distinct collagen types described, of which type I-commonly found in connective tissues, including tendons, bones and skin is one of the most studied [7]. It is characterized by an amino acid sequence - glycine (Gly), proline (Pro), Y, Gly, $\mathrm{X}$ and hydroxyproline (Hyp), where $\mathrm{Y}$ and $\mathrm{X}$ are any amino acid-arranged in a triple-helical conformation. The repeated unit could be represented by the following sequence: (Gly-Pro-Y-Gly-X-Hyp). This structure is stabilized by inter and intramolecular hydrogen

\footnotetext{
*Corresponding author.
}

bonds among the amide groups of the backbone chain amino acids [8-10]. Collagen has biomedical, cosmetic and pharmaceutical applications, among others [11,12].

Gelatin - denatured collagen - is a heterogeneous mixture of water-soluble proteins with high molecular weight. Denaturation requires acid or alkaline pretreatment. Additional heat breaks the hydrogen and covalent bonds, leading to triple-helix rupture [13-16].

Recently, composites based on collagen/hydroxyapatite have been studied for bone and dental repairs $[17,18]$. Sol-gel, precipitation, biomimetic and hydrothermal processes are synthesis routes to produce collagen/hydroxyapatite composites $[19,20]$. Among them, precipitation is one of the most often used because it can produce a large amount of hydroxyapatite without organic solvent. A material with morphology similar to compact bone was found by Ficai and colleagues [21] based on COLL/ HA composite produced though the precipitation method. A biomimetic process was used by Wang and colleagues [22] to produce composite by deposition of HA onto a collagen substrate. The Ca:P molar ratio was 1.58 , very close to that of bone tissue. Using a similar process but different precursors, Ficai and colleagues [23] produced a collagen polymeric substrate containing HA crystals on its surface.

The purpose of this work was to study the influence of collagen on the structural and morphological characteris- 
tics HA crystals synthesized in situ.

\section{Experimental}

\subsection{Materials}

The collagen type I was purchased from Proquimios (Rio de Janeiro, Brazil). The inorganic materials-calcium nitrate tetrahydrate $\mathrm{Ca}\left(\mathrm{NO}_{3}\right)_{2} \cdot 4 \mathrm{H}_{2} \mathrm{O}$, ammonium phosphate $\left(\mathrm{NH}_{4}\right)_{2} \mathrm{HPO}_{4}$ and ammonium hydroxide $\left(\mathrm{NH}_{4} \mathrm{OH}\right)$ -were used for HA synthesis and were purchased from Vetec Química Fina Ltda. (Rio de Janeiro).

\subsection{Hydroxyapatite Synthesis in the Presence of Collagen}

Hydroxyapatite in the presence of collagen was prepared as follows. Two aqueous solutions were prepared: Solution A- $62.5 \mathrm{~mL}$ of calcium nitrate tetrahydrate $\mathrm{Ca}$ $\left(\mathrm{NO}_{3}\right)_{2} \cdot 4 \mathrm{H}_{2} \mathrm{O}(2.42 \mathrm{M})$, containing collagen (3.96 grams), and Solution $\mathrm{B}-62.5$ of $\mathrm{mL}$ ammonium phosphate $\left(\mathrm{NH}_{4}\right)_{2} \mathrm{HPO}_{4}(1.48 \mathrm{M})$. The $\mathrm{pH}$ of both was adjusted in the range $10-11$ using ammonium hydroxide $\left(\mathrm{NH}_{4} \mathrm{OH}\right)$ $(8 \mathrm{M})$. The $\mathrm{B}$ solution was dripped onto the A solution, under mechanical stirring $(350 \mathrm{rpm})$, flow rate of $100 \mathrm{~mL} / \mathrm{h}$ and temperature of $80^{\circ} \mathrm{C}$ for approximately $40 \mathrm{~min}$. After this period, the reaction medium was kept under mechanical stirring for 2 hours. In order to compare the results, hydroxyapatite without collagen was synthesized using the same method. To avoiding removing the collagen - water soluble material-the samples were freeze dried instead of being washed in water [24].

\subsection{Fourier Transform Infrared Spectroscopy (FT-IR)}

FT-IR spectra of the samples were obtained using a Varian model 3100 Excalibur Series spectrometer, with resolution of $2 \mathrm{~cm}^{-1}$ and 40 scans, in the range of 4000 $400 \mathrm{~cm}^{-1}$, from a $\mathrm{KBr}$ disk, to evaluate the interactions between the COLL and HA.

\subsection{Thermogravimetry/Differential Thermogravimetry (TG/DTG)}

The thermal stability of the samples was estimated by thermogravimetry/differential thermogravimetry curves, registered in a TA Instruments model Q500 analyzer, from $30^{\circ} \mathrm{C}$ to $700^{\circ} \mathrm{C}$ at $10^{\circ} / \mathrm{min}$, under nitrogen atmosphere. The initial, final and maximum degradation temperatures were measured.

\subsection{Energy-Dispersive X-Ray Spectroscopy (EDX)}

The $\mathrm{Ca} / \mathrm{P}$ ratio of the $\mathrm{HA}$, with and without collagen, was determined X-ray energy-dispersive spectroscopy using a Shimadzu model 720 spectroscope.

\subsection{Wide-Angle Diffraction (WAXD)}

Wide-angle X-ray diffraction was performed in a Rigaku Miniflex diffractometer using $\mathrm{Cu} \mathrm{K} \alpha$ radiation at $30 \mathrm{~mA}$, $40 \mathrm{kV}$ and $2 \theta$ scans from $2^{\circ}$ to $60^{\circ}$, to assess the crystalline structure and changes in the $2 \theta$ reflection angles of the HA.

The crystallinity degree $\left(\mathrm{X}_{\mathrm{c}}\right)$ of both HA types was calculated using the values given by the Fityk program, through the ratio of crystallinity and total area of the diffractogram peaks. The average size of the HA crystallites was obtained using the full width at half maximum (FWHM) of each diffractogram, using Scherrer's equation Equation (1) $[25,26]$ where $K$ is the Scherrer constant, $(\mathrm{FWHM})=1, \beta$ is a measure of the line broadening, $\lambda$ is the wavelength of the X-ray $=1.5418 \AA$, and $\theta$ is the angular position of the reflection peak. Bragg's law Equation (2) was used to determine the spacing of the crystallographic planes, where $n$ is an integer, $\lambda$ is the incident wavelength, $d$ is the spacing between planes in the atomic structure, and $\theta$ is the angle between the incident ray and the scattering planes [27,28].

$$
\begin{gathered}
\tau=\frac{K \lambda}{\beta \cos \theta} \\
n \lambda=2 d \sin \theta
\end{gathered}
$$

\subsection{Scanning Electron Microscopy (SEM)}

The morphological features of the materials were investigated with a GO model JSN5610LV scanning electron microscope. The powder was coated with a gold layer and the images were taken using 3.000 and 6.000 magnifications.

\section{Discussion}

\subsection{Fourier Transform Infrared Spectroscopy (FT-IR)}

Figures 1 and 2 show the FT-IR spectra of the collagen and both HA types, respectively. The collagen's characteristic absorptions were $1644 \mathrm{~cm}^{-1}$ (amide I, C=O), 1538 $\mathrm{cm}^{-1}$ (amide II, N-H stretching and C-N deformation), $1456 \mathrm{~cm}^{-1}$ (C-N deformation), $1234 \mathrm{~cm}^{-1}$ (amide III, C-N deformation and N-H stretching), $2842 \mathrm{~cm}^{-1}\left(\mathrm{CH}_{2}\right.$ asymmetric stretching), $2919 \mathrm{~cm}^{-1}\left(\mathrm{CH}_{2}\right.$ symmetric stretching) and $2849 \mathrm{~cm}^{-1}\left(\mathrm{CH}_{3}\right.$ symmetric stretching). The band shown at $3071-3470 \mathrm{~cm}^{-1}$ corresponds to associated-OH [29]. A high resolution HA spectrum without collagen was achieved. The $\mathrm{PO}_{4}^{3-} 470,562,601$, 962, 1035 and P-O $1106 \mathrm{~cm}^{-1}$ absorptions were attributed to the bending and symmetric stretching vibrations. 


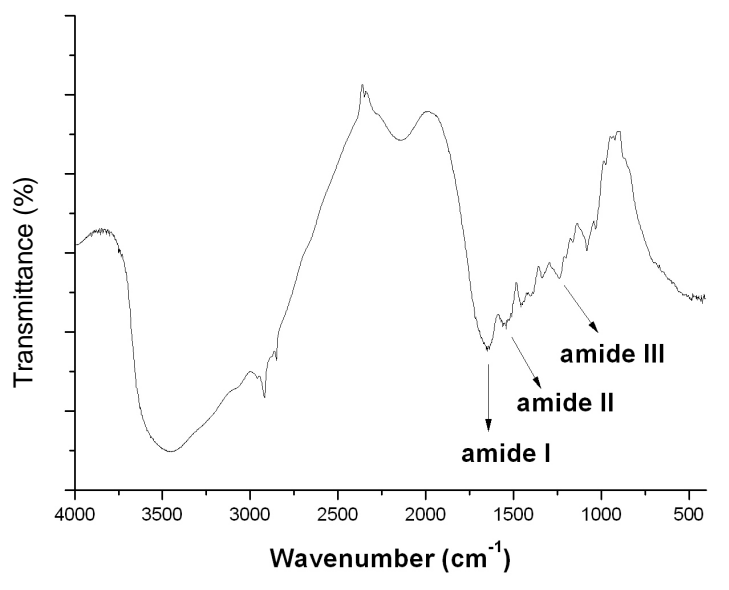

Figure 1. FT-IR spectra of the collagen.

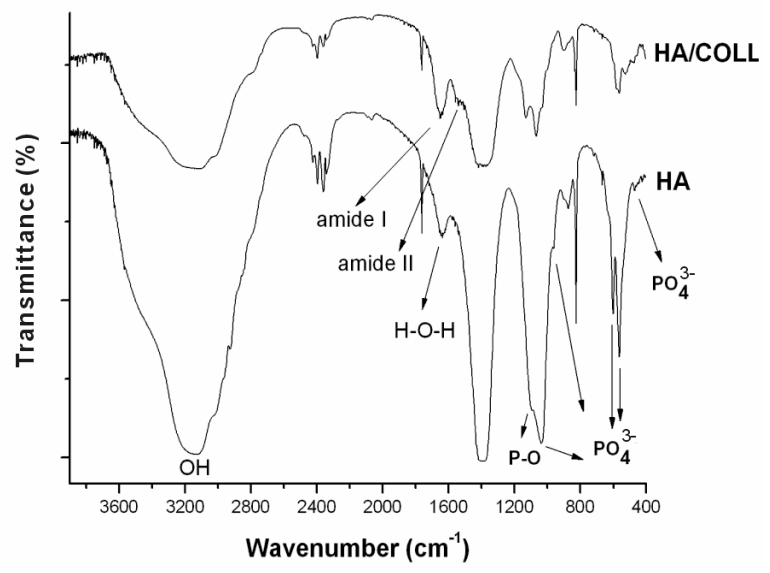

Figure 2. FT-IR spectra of the hydroxyapatite with and without collagen.

The -OH stretching absorption is composed of a shoulder $\left(3575 \mathrm{~cm}^{-1}\right)$ and a peak at $3493 \mathrm{~cm}^{-1}$, associated and free, respectively. The $-\mathrm{OH}$ bending vibration appeared as a weak peak at low frequency $\left(669 \mathrm{~cm}^{-1}\right)[30]$. The absorption at $1644 \mathrm{~cm}^{-1}$ could be ascribed to two types of vibrations - in plane $\mathrm{H}-\mathrm{O}-\mathrm{H}$ bending (water) and carbonyl stretching (carbon dioxide). Concerning the HA with collagen, the main HA absorptions could be detected but some peaks were merged with the collagen indicating some chemical interactions.

\subsection{Thermogravimetry/Differential Thermogravimetry (TG/DTG)}

The TG/DTG curves are shown in Figures 3 and 4. Table 1 contains the degradation onset temperature $\left(\mathrm{T}_{\text {onset }}\right)$, maximum temperature $\left(T_{\max }\right)$ and final temperature $\left(T_{\text {end }}\right)$, as well as the residue content. The collagen thermal curve showed two stages of degradation. The first $\left(25^{\circ} \mathrm{C}\right.$ $-200^{\circ} \mathrm{C}, 8 \%$ ) could be attributed to the loss of water and the second $\left(270^{\circ} \mathrm{C}-500^{\circ} \mathrm{C}, 65 \%\right)$ to polymer chain degradation. The HA's thermal curve without collagen showed only one stage of degradation $\left(150^{\circ} \mathrm{C}-235^{\circ} \mathrm{C}\right)$, associated with the loss of water along with residue. In contrast, the thermal curve of the HA synthesized with collagen showed two stages of degradation. The initial stage was similar to that of HA without collagen, while the second one appeared at higher temperature $\left(425^{\circ} \mathrm{C}-450^{\circ} \mathrm{C}\right)$. This could indicate some chemical and/or physical interactions between components, leading to an increase of the collagen's thermal stability [31].

\subsection{Energy-Dispersive X-Ray Spectroscopy (EDX)}

$\mathrm{Ca} / \mathrm{P}$ ratios of 1.89 and 2.38 were calculated for $\mathrm{HA}$ without and with collagen, respectively. The first value is near the theoretical value (1.67) considering the repeat unit of the HA chemical structure- $\mathrm{Ca}_{10}\left(\mathrm{PO}_{4}\right)_{6}(\mathrm{OH})_{2}$ [3]. The addition of collagen influenced the HA chain growth. The chain catenation and the repeat unit were modified. Figure 5 shows the schematic representation of the feasible repeat unit of the HA, with and without collagen.

\subsection{Wide-Angle Diffraction (WAXD)}

The WAXD diffractograms are shown in Figure 6. The Bragg's angles and crystallographic planes of both HA types are shown in Table 2. The diffraction pattern of collagen reflects an amorphous material. The $2 \theta$ diffraction peaks of the HA without collagen $\left(26.4^{\circ} ; 29.35^{\circ} ; 32^{\circ}\right.$; $33.3^{\circ} ; 34.2^{\circ}$; and $40.5^{\circ}$ ) are associated to the crystallographic plans $(002,102,112,300,202$ and 310) of the apatite structure [32]. In the presence of collagen, the HA diffraction peaks are similar to the former but resolution and intensity are higher. The HA crystal seems to grow

Table 1. TG/DTG parameters of the COLL, HA and HA/COLL.

\begin{tabular}{|c|c|c|c|c|c|c|}
\hline \multirow{2}{*}{ Samples } & \multicolumn{2}{|c|}{$1^{\circ}$ stage } & \multicolumn{2}{|c|}{$2^{\circ}$ stage } & \multirow{2}{*}{ Degradation content (\%) } & \multirow{2}{*}{$\mathrm{T}_{\max }\left({ }^{\circ} \mathrm{C}\right)$} \\
\hline & $\mathrm{T}_{\text {onset }}\left({ }^{\circ} \mathrm{C}\right)$ & $\mathrm{T}_{\text {end }}\left({ }^{\circ} \mathrm{C}\right)$ & $\mathrm{T}_{\text {onset }}\left({ }^{\circ} \mathrm{C}\right)$ & $\mathrm{T}_{\mathrm{end}}\left({ }^{\circ} \mathrm{C}\right)$ & & \\
\hline HA & 150 & 235 & - & - & 52.19 & 236.64 \\
\hline COLL & 25 & 200 & 270 & 500 & 25.44 & 320.87 \\
\hline $\mathrm{HA} / \mathrm{COLL}$ & 25 & 200 & 425 & 450 & 46.52 & 232.61 \\
\hline
\end{tabular}




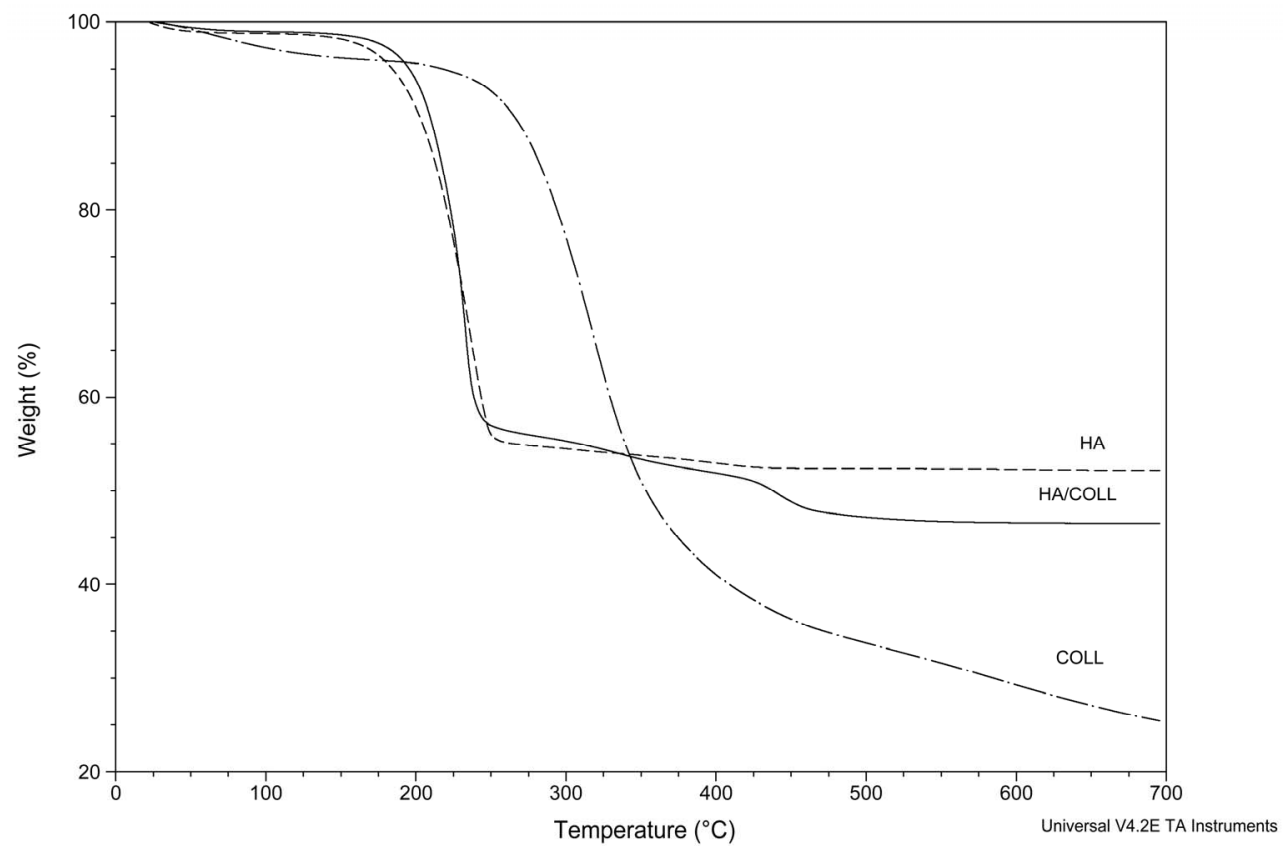

Figure 3. TG curves of collagen, HA and HA/COLL.

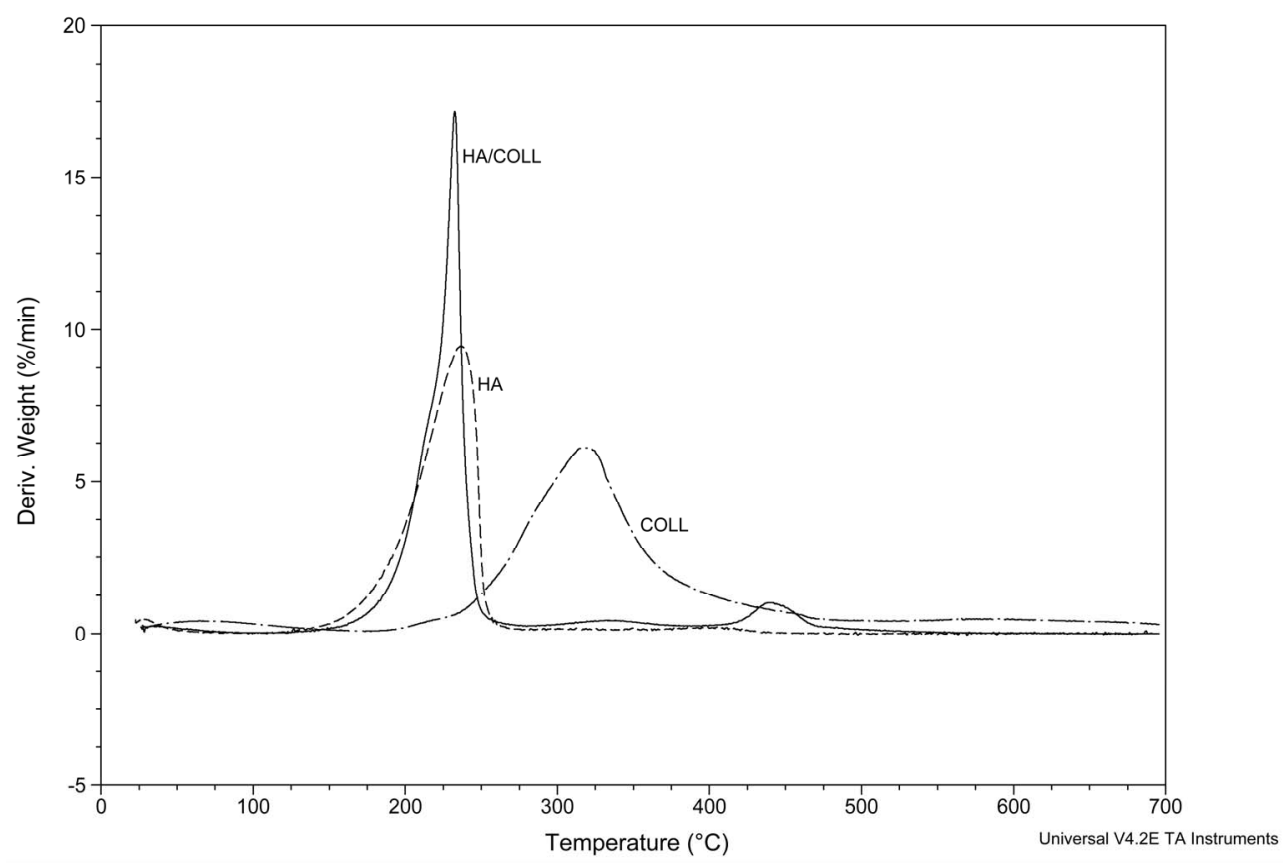

Figure 4. DTG curves of collagen, HA and HA/COLL.

preferentially toward the crystallographic plane related to the $2 \theta$ diffraction angle, equal to 33, as reported by Ficai and colleagues [19]. The crystallinity degrees $\left(\mathrm{X}_{\mathrm{c}}\right)$ were $58 \%$ and $75 \%$, for the HA without and with collagen, respectively. The increase denotes that the collagen seems to play a role as nucleating agent of the HA. The interplanar distance value $(0.48 \AA)$ was the same for both HA types [28,29].

\subsection{Scanning Electron Microscopy (SEM)}

The SEM photomicrographs of the materials are shown in Figure 7. The images revealed morphological differences between the two hydroxyapatites. The HA synthesized in the presence of collagen showed morphology similar to regular microrods. In the absence of collagen, irregular cluster morphology was achieved. 


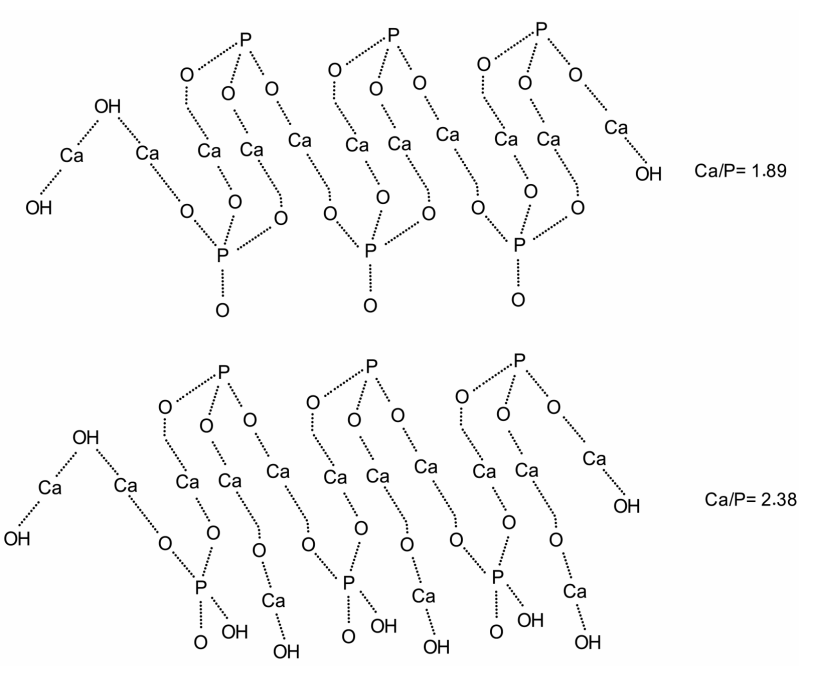

Figure 5. Schematic representation of the feasible repeat unit of the HA: $\mathrm{Ca} / \mathrm{P}=\mathbf{1 . 8 9}$ and 2.38 , without and with collagen, respectively.

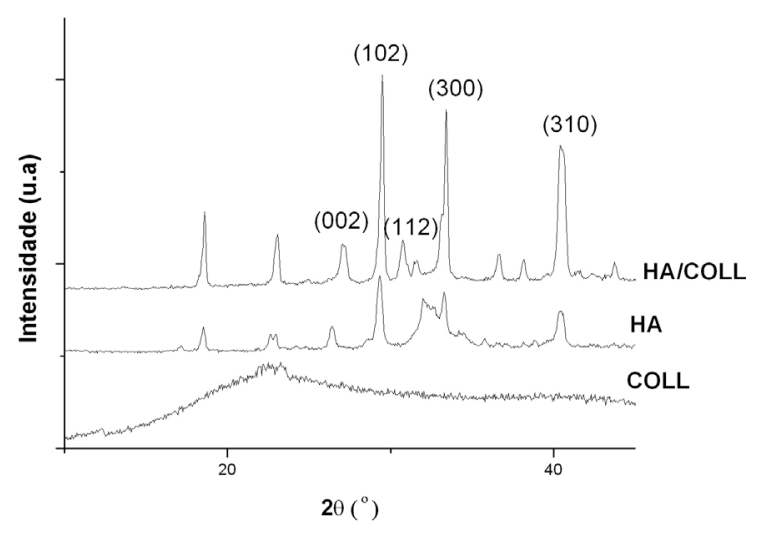

Figure 6. WAXD of the HA, COLL and HA/COLL materials.

Table 2. Bragg angle and crystallographic planes of the HA and HA/COLL.

\begin{tabular}{ccc}
\hline \multirow{2}{*}{ Crystalografic plans } & \multicolumn{2}{c}{ Bragg angle/2 $\theta$} \\
\cline { 2 - 3 } & HA & HA/COLL \\
\hline$(002)$ & 26.4 & 26.9 \\
$(102)$ & 29.35 & 29.5 \\
$(112)$ & 32 & 30.7 \\
$(300)$ & 33.3 & 33.4 \\
$(202)$ & 34.2 & - \\
$(310)$ & 40.5 & 40.4 \\
\hline
\end{tabular}

\section{Conclusion}

The influence of collagen on the structural and morphological characteristics of synthesized hydroxyapatite was investigated. The TG/DTG and FT-IR analyses indicated

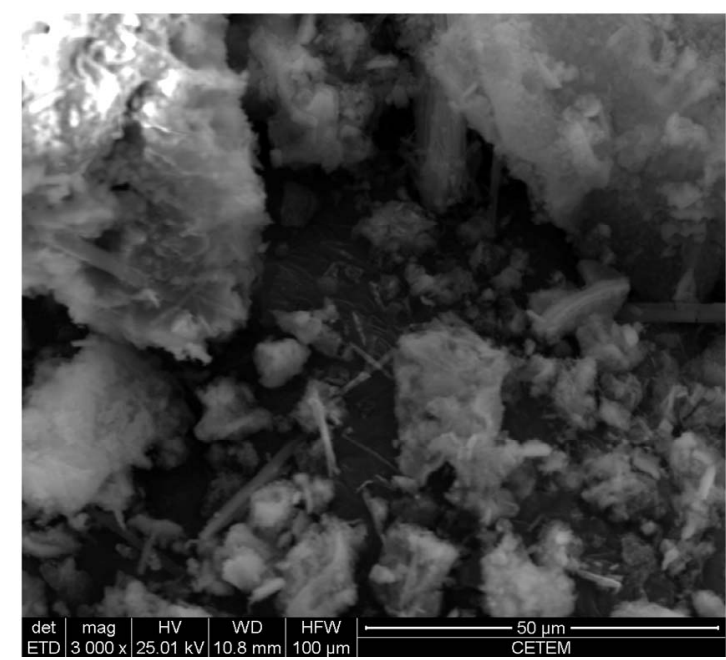

(a)

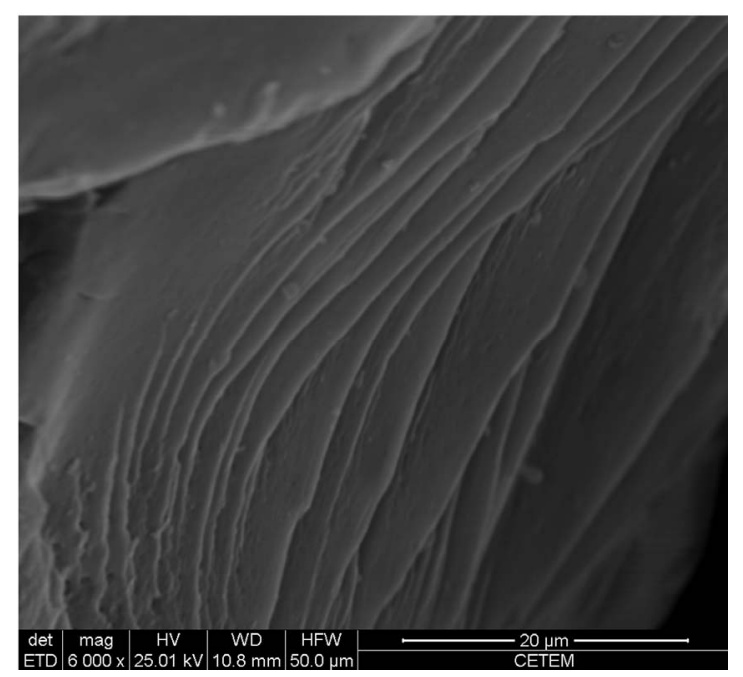

(b)

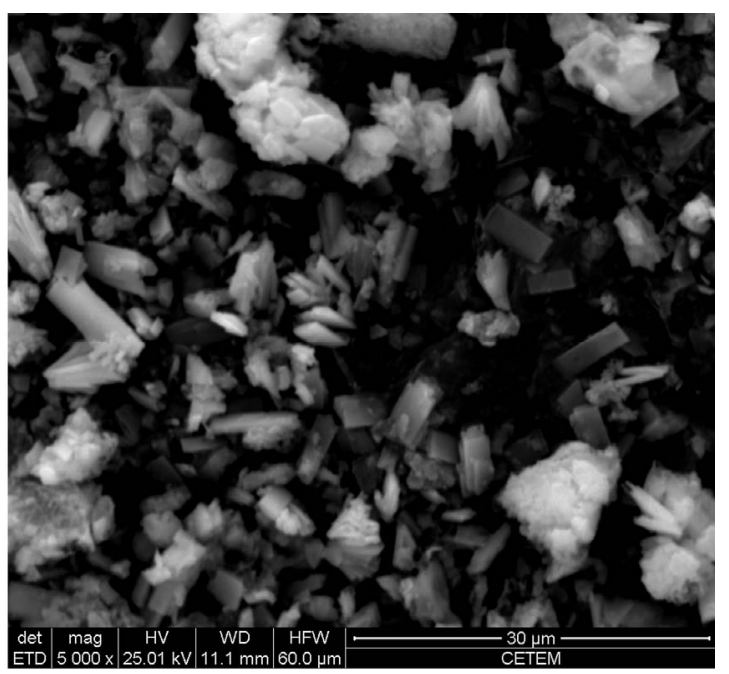

(c)

Figure 7. SEM photomicrographs of the HA (a); COLL (b); HA/COLL (c). 
that chemical and/or physical interaction between the HA and collagen could have existed. Structural differences with respect to the HA repeat unit was indicated by EDX. The WAXD revealed that the crystallinity degree was higher in the HA produced in the presence of collagen. SEM images showed strong action of the collagen on the HA's morphology.

\section{Acknowledgements}

The authors thanks the National Council for Scientific and Technological Development (CNPq), National Council for the Improvement of Higher Education (CAPES) and Federal University of Rio de Janeiro (UFRJ).

\section{REFERENCES}

[1] R. K. Brundavanam, Z. T. Jiang, P. Chapman, X. T. Lê, N. Mondinod, D. Fawcett and G. E. J. Poinem, "Effect of Dilute Gelatine on the Ultrasonic Thermally Assisted Synthesis of Nano Hydroxyapatite," Ultrasonics Sonochemistry, Vol. 18, No. 3, 2011, pp. 697-703. doi:10.1016/j.ultsonch.2010.11.007

[2] K. Sato, Y. Hotta, T. Nagaoka, M. Yasuoka and K. Watari, "Agglomeration Control of Hydroxyapatite NanoCrystals Grown in Phase-Separated Microenvironments," Journal of Materials Science, Vol. 41, No. 17, 2006, pp. 5424-5428. doi:10.1007/s10853-006-0258-6

[3] A. S. Fomin, S. M. Barinov, V. M. Ielev, V. V. Smirnov, B. P. Mikhailov, S. V. Kutsev, E. K. Belongov and N. A. Drozdova, "Nanocrystalline Hydroxyapatite Ceramics," Inorganic Materials, Vol. 41, No. 10, 2009, pp. 11931196. doi:10.1134/S0020168509100203

[4] G. Zuo, C. Liu, H. Luo, F. He, H. Liang, J. Wang and Y. Wan, "Synthesis of Intercalated Lamellar Hydroxyapatite/ Gelatin Nanocomposite for Bone Substitute Application," Journal of Applied Polymer Science, Vol. 113, No. 5, 2009, pp. 3089-3094.

[5] Y. J. Yin, F. Zhao, X. F. Song, K. D. Yao, W. W. Lu and J. C. Leong, "Preparation and Characterization of Hydroxyapatite/Chitosan-Gelatin Network Composite," Journal of Applied Polymer Science, Vol. 77, No. 13, 2000, pp. 2929-2938.

doi:10.1002/1097-4628(20000923)77:13<2929::AID-AP P16>3.0.CO;2-Q

[6] K.-L. Ou, R.-J. Chung, F.-Y. Tsai, P.-Y. Liang, S.-W. Huang and S.-Y. Chang, "Effect of Collagen on the Mechanical Properties of Hydroxyapatite Coatings," Journal of the Mechanical Behavior of Biomedical Materials, Vol. 4, No. 4, 2011, pp. 618-624.

[7] K. Gelse, E. Poschl and T. Aigner, "Collagens-Structure, Function, and Biosynthesis," Advanced Drug Delyvery Reviews, Vol. 55, No. 12, 2003, pp. 1531-1546. doi:10.1016/j.addr.2003.08.002

[8] P. Singh, S. Benjakul, S. Maqsood and H. Kishimura, "Isolation and Characterization of Collagen Extrated from the Skin of Striped Catfish (Pangasianodon hypophthalmus)," Food Chemistry, Vol. 124, No. 1, 2011, pp. 97-
105. doi:10.1016/j.foodchem.2010.05.111

[9] W. Friess, "Collagen-Biomaterial for Drug Delivery," European Journal of Pharmaceutcs and Biopharmaceutcs, Vol. 45, No. 2, 1998, pp. 113-136. doi:10.1016/S0939-6411(98)00017-4

[10] S. Ricard-Blum and F. Ruggiero, "The Collagen Superfamily: From the Extracellular Matrix to the Cell Membrane," Pathoogie Biologie, Vol. 53, No. 7, 2005, pp. 430-442. doi:10.1016/j.patbio.2004.12.024

[11] H. W. Kim, H. E. Kim and V. Salih, "Stimulation of Osteoblast Responses to Biomimetic Nanocomposites of Gelatin-Hydroxyapatite for Tissue Engineering Scaffolds," Biomaterials, Vol. 26, No. 25, 2005, pp. 5221-5230. doi:10.1016/j.biomaterials.2005.01.047

[12] D. I. Zeugolis, S. T. Khew, E. S. Y. Yew, A. K. Ekaputra, Y. W. Tong, L.-Y. L. Yung, D. W. Hutmacher, C. Sheppard and M. Raghunath, "Electro-Spinning of Pure Collagen Nano-Fibers-Just an Expensive Way to Make Gelatin?" Biomaterials, Vol. 29, No. 15, 2008, pp. 22932305. doi:10.1016/j.biomaterials.2008.02.009

[13] A. A. Haroum, H. H. Beherei and M. A. Abd El-Ghaffar, "Preparation, Characterization, and in Vitro Application of Composite Films Based on Gelatin and Collagen from Natural Resources," Journal of Applied Polymer Science, Vol. 116, No. 4, 2010, pp. 2083-2094.

[14] H. Staroszczyk, J. Pielichowska, K. Sztuka, J. Stangret and I. kolodziejska, "Molecular and Structural Characteristics of Cod Gelatin Films Modified with EDC and Tgase," Food Chemistry, Vol. 130, No. 15, 2012, pp. 335-343. doi:10.1016/j.foodchem.2011.07.047

[15] F. Cúneo, L. Costa-Paiva, A. M. Pinto-Neto, S. S. Morais and J. Amaya-Frafan, "Effect of Dietary Supplementation with Collagen Hydrolysates on Bone Metabolism of Postmenopausal Women with Low Mineral Density," Maturitas, Vol. 65, No. 3, 2010, pp. 253-257.

doi:10.1016/j.maturitas.2009.10.002

[16] B. Giménez, A. Alemán, P. Montero, M. C. GómezGuillén, "Antioxidant and Functional Properties of Gelatin Hydrolysates Obtained from Skin of Sole and Squid," Food Chemistry, Vol. 114, No. 3, 2009, pp. 976-983. doi:10.1016/j.foodchem.2008.10.050

[17] S. Hillson, "Teeth," Cambridge University Press, New York, 2005. doi:10.1017/CBO9780511614477

[18] L. Zhang, P. Tang, M. Xu, W. Zhang, W. Chai and Y. Wang, "Effects of Crystalline Phase On The Biological Properties of Collagen-Hydroxyapatite Composites," Acta Biomaterialia, Vol. 6, No. 6, 2010, pp. 2189-2199.

[19] A. Ficai, E. Androsceneu, G. Voicu, C. Ghitulica and D. Ficai, "The Influence of Collagen Support and Ionic Species on the Morphology of Collagen/Hydroxyapatite Compsite Materials," Materials Characterization, Vol. 61, No. 4, 2010, pp. 402-407. doi:10.1016/j.matchar.2010.01.003

[20] V. P. Orlovskii,. V. S. Komlev and S. M. Barinov, "Hydroxyapatite and Hydroxyapatite-Based Ceramics," Inorganic Mateials, Vol. 38, No. 10, 2002, pp. 1159-1172. doi:10.1023/A:1020585800572

[21] A. Ficai, E. Androsceneu, G. Voicu, C. Ghitulica and B. S. 
Vasile, "Self-Assembled Collagen/Hydroxyapatite Composite Materials," Chemical Engineering Journal, Vol. 160, No. 2, 2010, pp. 794-800. doi:10.1016/j.cej.2010.03.088

[22] B. Y. Wang, C. Yang, X. Chen and N. Zhao, "Biomimetic Formation of Hydroxyapatite/Collagen Matrix Composite," Advanced Engineering Materials, Vol. 8, No. 1-2, 2006, pp. 97-100. doi:10.1002/adem.200500220

[23] A. Ficai, E. Andronescu, G. Voicu, D. Manzu and M. Ficai, "Layer by Layer Deposition of Hydroxyapatite onto the Collagen Matrix," Materials Science and Engineering C, Vol. 29, No. 7, 2009, pp. 2217-2220. doi:10.1016/j.msec.2009.05.005

[24] L. C. Mendes, R. C. Rodrigues and E. P. Silva, "Thermal, Structural and Morphological Assessment of PVP/HA Composites," Journal of Thermal Analysis Calorimetric, Vol. 101, No. 3, 2010, pp. 899-905. doi:10.1007/s10973-010-0835-4

[25] H. Y. Jeong, J. H. Lee and K. F. Hayes, "Characterization of Synthetic Nanocrystalline Mackinawite: Crystal Structure, Particle Size, and Specific Surface Area," Geochimica et Cosmochimica Acta, Vol. 72, No. 2, 2008, pp. 493-505. doi:10.1016/j.gca.2007.11.008

[26] T.-G. Kim and B. Park, "Synthesis and Growth Mechanismis of One-Dimensional Strontium Hydroxyapatite Nanostructures," Inorganic Chemistry, Vol. 44, No. 26, 2005, pp. 9895-9901. doi:10.1021/ic051013m

[27] W.-J. Shih, Y.-F. Chen, M.-C. Wang and M.-H. Hon,
"Crystals Growth and Morphology of the Nano-Sized Hydroxyapatite Powders Synthesized from $\mathrm{CaHPO}_{4} \cdot 2 \mathrm{H}_{2} \mathrm{O}$ and $\mathrm{CaCO}_{3}$ by Hydrolysis Method," Journal of Crystal Growth, Vol. 270, No. 1-2, 2004, pp. 211-218. doi:10.1016/j.jcrysgro.2004.06.023

[28] Y. Sun, G. Guo, D. Tao and Z. Wang, "Reverse Microemulsion-Directed Synthesis Of Hydroxyapatite Nanoparticles Under Hydrotherma Conditions," Journal of Physics and Chemistry of Solids, Vol. 68, No. 3, 2007, pp 373-377. doi:10.1016/j.jpcs.2006.11.026

[29] M. C. Chang and J. Tanaka, "FT-IR Study for Hydroxyapatite/Collagen Nanocomposite Cross-Linked by Glutaraldehyde," Biomaterials, Vol. 23, No. 24, 2002, pp. 48114818. doi:10.1016/S0142-9612(02)00232-6

[30] M. Jevtic, A. Radulovic, N. Ignjatovic, M. Mitric and D. Uskokovic, "Controlled Assembly of Poly (D,L-LactideCo-Glycolide)/Hydroxyapatite Core-Shell Nanospheres under Ultrasonic Irradiation," Acta Biomaterialia, Vol. 5, No. 1, 2009, pp. 208-218. doi:10.1016/j.actbio.2008.07.026

[31] A. Sionkowska and J. Kozlowska, "Characterization of Collagen/Hydroxyapatite Composite Sponges as a Potential Bone Substitute," Interational Journal of Biological Macromolecules, Vol. 47, No. 4, 2010, pp. 483487. doi:10.1016/j.ijbiomac.2010.07.002

[32] S.-H. Teng, E.-J. Lee, P. Wang and H.-E. Kim, "Collagen/Hydroxyapatite Composite Nanofibers by Electrospinning," Materials Leters, Vol. 62, No. 17-18, 2008, pp. 3055-3058. doi:10.1016/j.matlet.2008.01.104 